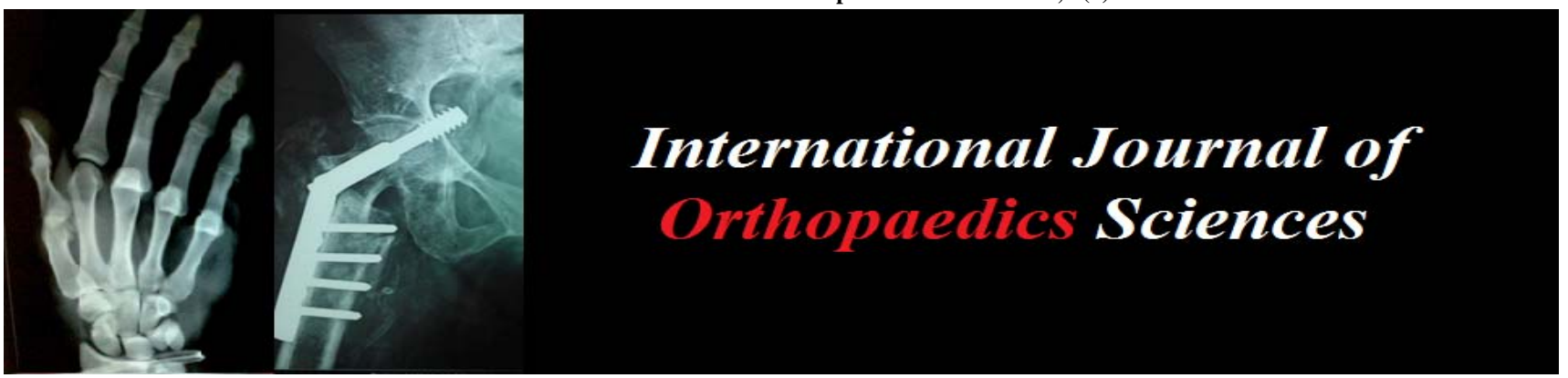

ISSN: $2395-1958$

IJOS 2017; 3(2): 99-109

(C) 2017 IJOS

www.orthopaper.com

Received: 19-02-2017

Accepted: 20-03-2017

Dr. S Ramanathan

M.S (Ortho), Assistant Professor,

Madurai Medical College,

Madurai, Tamil Nadu, India

Dr. S Mohan Kumar

D.Ortho, M.S (Ortho),

Assistant Professor,

Kanyakumari Govt Medical

College, Nagercoil, Tamil Nadu,

India

\section{A study on functional and radiological outcome in precontoured locking plate fixation for displaced lateral end of clavicle fractures}

\author{
Dr. S Ramanathan and Dr. S Mohan Kumar
}

DOI: http://dx.doi.org/10.22271/ortho.2017.v3.i2b.19

Abstract

Aim of the study: The aim of the study is to prospective analysis of functional and radiological outcome in precontoured locking plate fixation for displaced lateral end of clavicle fractures in terms of union, complications and functional outcome.

Materials and methods: In this prospective study 20 patients (15 male, 5 female) with a displaced lateral end of clavicle fractures (Neer type II) were evaluated with a mean follow -up of 11 months. Analysis included functional and subjective outcome, radiological outcome and complications.

Results: All patients achieved radiological union within 9-13 weeks (mean 11.35 weeks). Full range of motion achieved in most cases within 6 weeks. The mean UCLA score was 31.55 (range 27-35). At final follow-up radiographs showed mean coracoclavicular distance of $8.6 \mathrm{~mm}$ (range from $7.4 \mathrm{~mm}$ to $10.6 \mathrm{~mm}$ ) on the affected shoulder and $8.27 \mathrm{~mm}$ (range from $7.4 \mathrm{~mm}$ to $10.7 \mathrm{~mm}$ ) on the unaffected shoulder. No major complications were encountered intraoperatively. Three patients had postoperative complications: one patient required plate removal, because of a deep infection, one superficial infection treated with oral antibiotics alone, shoulder stiffness one case because of an improper physiotherapy.

Conclusions: In this study, use of the precontoured locking plate yielded excellent results in the treatment of this difficult fracture. In particular, patients acquired full range of motion within 6 weeks, reflecting the stability of the osteosynthesis achieved with this implant.

Keywords: Precontoured, lateral end of clavicle, osteosynthesis, outcome

\section{Introduction}

Of all fractures clavicle fractures account for $2.6 \%{ }^{[1,2]}$. Among the clavicle fractures, distal third fractures are the next most common type (20\%) after mid shaft fractures $(80 \%)$, and although they can result from the same mechanisms of injury as that seen with mid shaft of clavicle fractures. In elderly people even with simple falls clavicle fractures occur. In general the lateral end of clavicle fractures Neer type I and II can be treated nonoperatively, but Neer type II fractures are considered as unstable, because displacement of fragments due to the distraction forces (distal fragment distracted by the weight of the arm, lateral fragment by trapezius muscle). Therefore, the non-union rate reaches around $22 \%$ to $44 \%$ in these fractures. If the fracture fails to heal then these patients may develop persistent pain, movement restriction, and decrease strength of shoulder. Also treatment of nonunion lateral end of clavicle fracture is technically challenging. An increase in the incidence of lateral clavicle fractures is seen in elderly patients and conservative management in this age-group is not associated with significant functional loss in the presence of a non-union ${ }^{[16]}$. Even in young and active group of people, the functional impairment and pain caused by these fractures affects the quality of life. So that in younger patients with these fractures, operative treatment is more appropriate.

A range of techniques are described for fixation of these injuries including; plating (hookplate, locking T plates, ${ }^{[17,18]}$, coraco-clavicular screw ${ }^{[19]}$, Kirschner wires ${ }^{[20]}$ and Knowles pins ${ }^{[21]}$.

Neer described many techniques and methods for fixing these fractures; two transarticular Kwires fixation is a standing example ${ }^{[4,5]}$.
Dr. S Mohan Kumar

D.Ortho, M.S (Ortho),

Assistant Professor,

Kanyakumari Govt Medical College, Nagercoil, Tamil Nadu, India 
This indirectly suggests that these methods do not always yield the desired results ${ }^{[26]}$. In the last decade, the hook plateoriginally developed by Balser to treat acromioclavicular dislocations-has been used as treatment for this difficult fracture ${ }^{[27]}$. Due to the close relationship to the rotator cuff and the acromioclavicular joint (ACJ) hook plate cause impingement complaints. This plate has gained some negative publicity because of the obligation to remove the implant after fracture union.

While fixing with a standard distal clavicle plate, three screws (a minimum of two) should be placed in the distal fragment to provide sufficient stability ${ }^{[22]}$. The relatively recent introduction of contoured plates (such as the locking $\mathrm{T}$ plate) allows more screws to be placed in the distal fragment, which may improve stability ${ }^{[23]}$. Clinical results with pre-contoured plating systems have been positive, with a number of authors reporting good functional outcomes and few complications ${ }^{[17}$, 24, 25]. Martetschlager et al. ${ }^{[17]}$ treated 30 patients with a locking $\mathrm{T}$ plate and supplementary PDS circlage suturing, achieving union within 10 weeks and good or excellent functional outcomes with a return to premorbid levels of activity in all cases. These results were supported in a recent report by Kang et al ${ }^{[24]}$. in a group of 10 patients with nonunions of the distal ends of the clavicle. Mean time to union was 14 weeks, with all patients demonstrating good or excellent functional scores at final follow up of 24 months.

Different methods that are used to fix the lateral end of clavicle fractures have been proposed because of the difficult

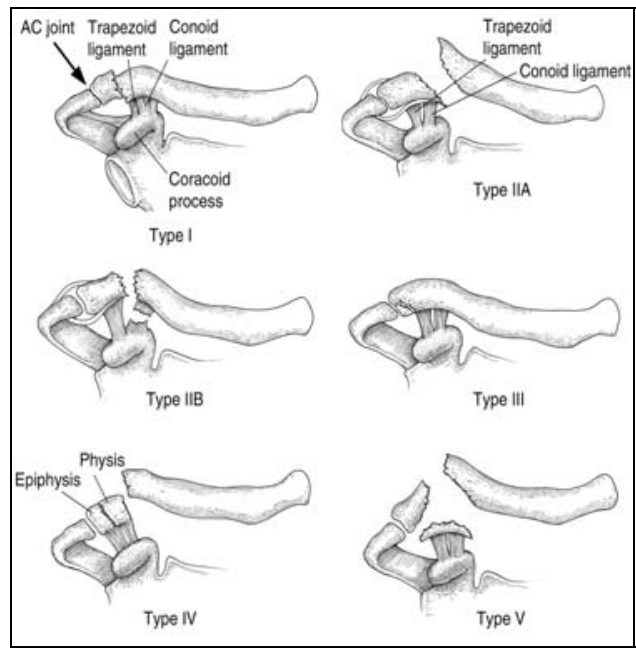

\section{Materials and Methods}

Study is conducted in the Department of Orthopaedics and Traumatology, Madurai Medical College and Government Rajaji Hospital on 20 patients with displaced/comminuted lateral end of clavicle fractures from July 2014 to August 2015.

All the patients were treated with $3.5 \mathrm{~mm}$ precontoured locking plates.

\section{Criteria for Inclusion}

Patients were included in the study if they had (1) Neer type II fractures, (2) unilateral fractures, (3) Simple injuries, (4) normal shoulder function before injury,(5) an age between twenty one and seventy five

\section{Criteria for Exclusion}

Patients were excluded from the study if they had (1) Acromioclavicular joint dislocation, (2) pathological nature of these fractures. Because of the soft, short distal metaphyseal end of these types of fractures, it is impossible to fix the lateral end of clavicle with conventional plates and screws with sufficient stability to allow early active mobilization of the shoulder joint.

Based on the high rates of non-union, difficult rehabilitation and residual shoulder pain associated with nonoperative treatment in several studies, many surgeons recommend operative treatment for type II fractures.

So we decided to evaluate functional and radiological outcome in patients treated with precontoured locking plate for type II distal end of clavicular fractures.

\section{Classification of Clavicle Fracture}

Robinson analyzed clavicle fractures over a six year period at Orthopaedic Trauma Unit of the Royal Infirmary of Edinburgh and he described his own classification. His classifications include important prognostic variables such as comminution, degree of displacement and intra-articular extent.

Neer analyzed lateral end of clavicle fractures, because of their high rate of delayed and non-union, Neer divided distal clavicle fractures into three subgroups, based on their ligamentous attachments and degree of displacement (type II was modified by Rockwood).

\section{Neer’s Classification}

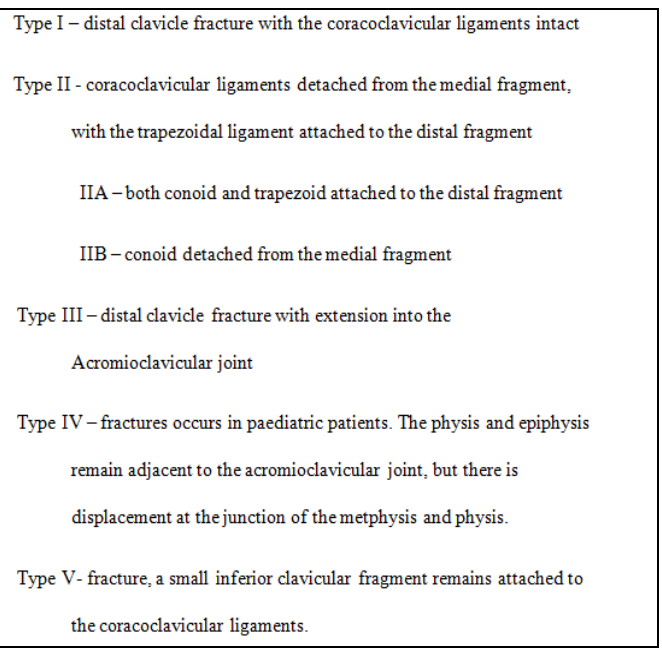

fractures, (3) previous surgery on the injured clavicle or shoulder, (4) hemiparesis (on the affected side).

\section{Implant Design}

Precontoured locking compression plates are superior clavicle plate with lateral extension, as they have holes for $2.4 \mathrm{~mm}$ cortical or $2.7 \mathrm{~mm}$ locking screws and the medial part of the plates have holes for $3.5 \mathrm{~mm}$ locking or cortical screws. The lateral end is $20 \mathrm{~mm}$ wider; which perfectly matches with the shape of lateral end of clavicle. On lateral aspect, the plates have holes six in numbers that are in different angles, which one increases pull-out strength and improve overall plate stability regardless of bone quality, especially in osteoporotic bone and soft metaphyseal bone of distal clavicle. Precontoured locking compression plate is a side specific plate and on the medial side of plate allows 3 to 8 holes. 


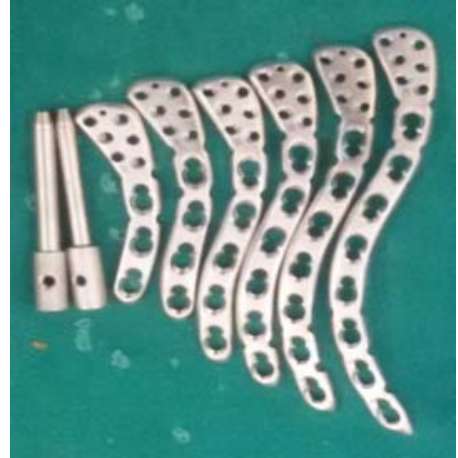

\section{Operative Technique}

Patient under general anaesthesia or interscalene anaesthesia was positioned in beach chair position on a radiolucent table. Involved shoulder is painted and draped and a curved incision is made over lateral third of clavicle.

Subperiostealy deltoid attachment was elevated. After identification of the fracture site, it was reduced; if any large comminuted fragments were present, they were temporarily fixed with K-wires. If there was any interposition of soft tissue, the same was removed. No repair was done if any ligaments were found torn. Location of acromioclavicular joint (ACJ), was marked with a needle and confirmed with $\mathrm{C}$ - arm magnification without opening the joint. Positioning of plate over lateral end of clavicle was checked in anteroposterior direction and acromioclavicular joint parallel with the most lateral end of plate. Foremost the plate was fixed with clavicle on the medial fragment with a cortical screw $(3.5 \mathrm{~mm})$, and $2.7 \mathrm{~mm}$ locking screw was applied on lateral end. Ultimately the remaining holes in the plate were filled with $3.5 \mathrm{~mm}$ locking screws. Lag screws were applied if Comminuted fragments were present, without disrupting soft tissue attachments of the fragment.

With number 1-prolene suture material fascia of deltotrapezium was closed with interrupted knots, as a distinct layer, followed by skin closure. Over the plate, soft tissue is covered in a full-thickness layers. No drains were used.

\section{Follow up}

- Postoperatively the limb was immobilised with sling. Active range of motion (ROM) exercises - elbow, wrist, and hand under the supervision of a physiotherapist.

- On $2^{\text {nd }}-3^{\text {rd }}$ postoperative day, Pendulum exercises of the shoulder joint with the arm in a sling were started. All patients were discharged after suture removal.

- At $4^{\text {th }}$ week the range of movements of the pendulum swings increased gradually up to $90^{\circ}$.

- After $4^{\text {th }}$ week the sling was removed and the patient was instructed to exercise the shoulder joint with active range of movements more than $90^{\circ}$.

- At 6th week full range of movements were obtained. All Patients were advised to return to light works and day to day activities as long as tolerable and radiologically acceptable.

- Until solid union of the fracture, patients are advised to avoid heavy manual work.

\section{Assessment}

- All Patients were assessed with a standard protocol in which they were assessed by fourth week, sixth week, and once in a month until union of bone clinically and radio graphically.
- Using University of California Los Angeles shoulder score rating scale systems, objective and subjective shoulder function was measured.

- Both an anteroposterior and a $10^{\circ}$ to $20^{\circ}$ cephalad tilted radiographs were made for each patient. The coracoclavicular distance was measured (in-between superior surface of the coracoid process and inferior surface of the clavicle)

\section{Results}

Twenty patients ( 15 male and 5 female), with most of them (40\%) aged below 30 years were studied between July 2014 and August 2015. All 20 patients had primary plate fixation for the fracture done. The mean follow up period was 11 months. Mean UCLA shoulder rating scale was 31.55 (range from 27-35) for the injured shoulder, mean time taken for bony union was 11.35 weeks (range from 9 to 13 weeks). At final follow-up radiographs showed mean coracoclavicular distance of $8.6 \mathrm{~mm}$ (range from $7.4 \mathrm{~mm}$ to $10.6 \mathrm{~mm}$ ) on the affected shoulder and $8.27 \mathrm{~mm}$ (range from $7.4 \mathrm{~mm}$ to $10.7 \mathrm{~mm}$ ) on the unaffected shoulder. No statistically significant difference between the affected and unaffected shoulders at final follow-up $(p=0.31)$. No intraoperative complications observed. Three postoperative complications was observed, one patient had superficial infection which controlled with oral antibiotics and cured, second patient had deep infection with shoulder stiffness for which she underwent surgery i.e. Implant removal done after third month of surgery. Third patient who was on improper physiotherapy developed shoulder stiffness.

\section{Age distribution}

Among 20 patients (100\%) eight patients were below 30years $(40 \%)$, next common age group was $41-50$ years $(30 \%)$. It indicates that distal clavicular fractures more commonly occurs in the young active adults.

\begin{tabular}{|c|c|c|c|c|c|c|}
\hline Age & $\mathbf{2 1 - 3 0}$ & $\mathbf{3 1 - 4 0}$ & $\mathbf{4 1 - 5 0}$ & $\mathbf{5 1 - 6 0}$ & $\mathbf{6 1 - 7 0}$ & $>\mathbf{7 0}$ \\
\hline No patients & 8 & 1 & 6 & 3 & 1 & 1 \\
\hline Percentage & $40 \%$ & $5 \%$ & $30 \%$ & $15 \%$ & $5 \%$ & $5 \%$ \\
\hline
\end{tabular}

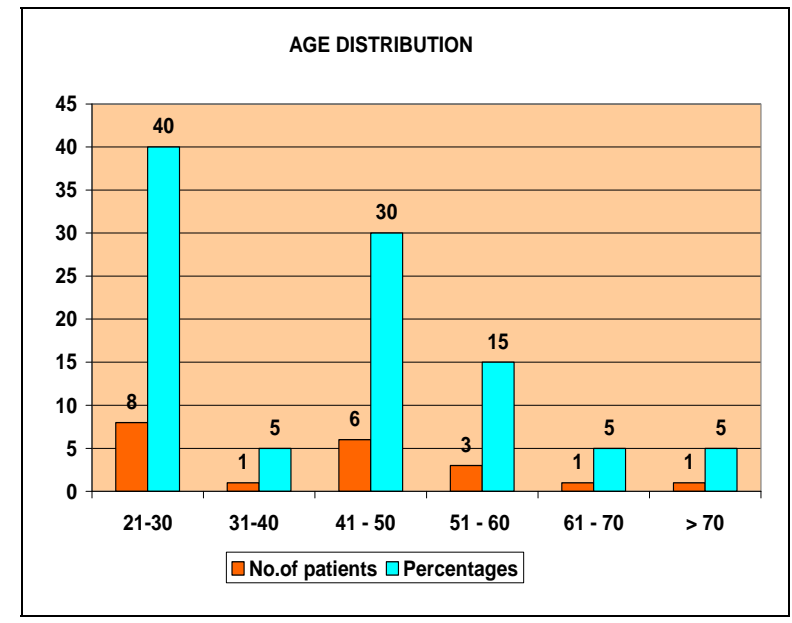

\section{Fracture types}

All 20 patients included in our study had Neer type II fracture of clavicle.

\begin{tabular}{|c|c|c|c|}
\hline Fracture type & No of patients & Percentage & Total \\
\hline Neer type II & 20 & $100 \%$ & 20 \\
\hline
\end{tabular}




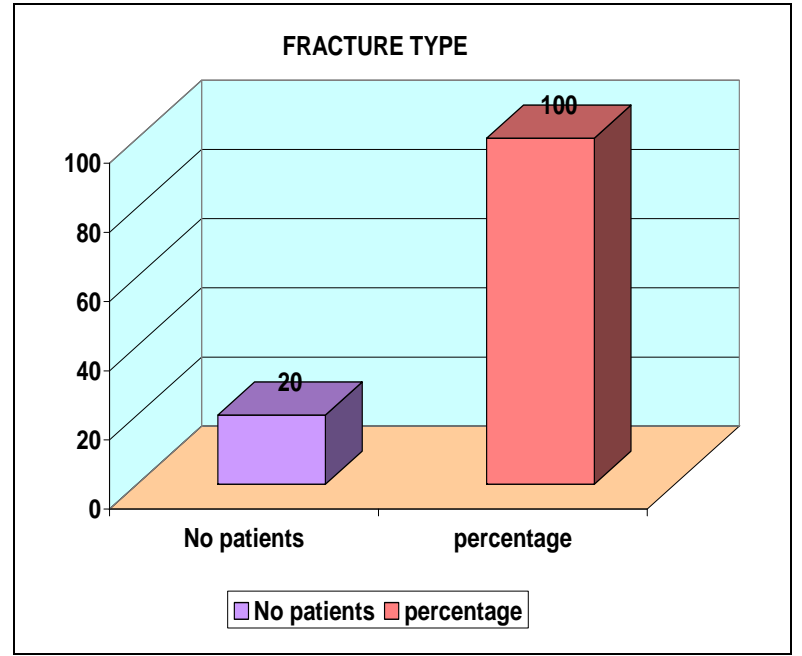

\section{Sex distribution}

Among 20 patients 15 were male, 5 were female patients

\begin{tabular}{|c|c|c|c|}
\hline Sex & Male & Female & Total \\
\hline No of patients & 15 & 5 & 20 \\
\hline Percentage & $75 \%$ & $25 \%$ & $100 \%$ \\
\hline
\end{tabular}

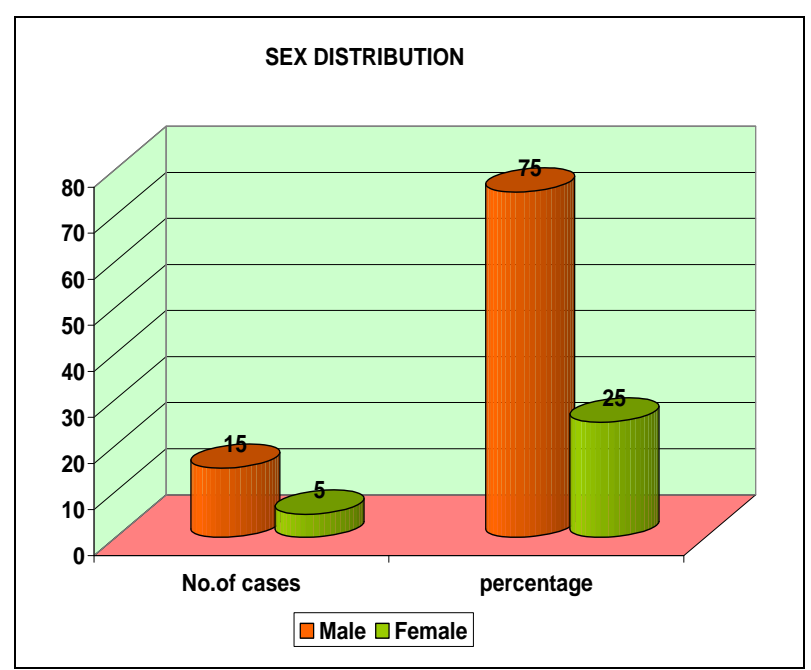

\section{Laterality distribution}

In total 20 patients, 9 patients had fracture of right side clavicle, 11 patients had fracture on left side clavicle.

\begin{tabular}{|c|c|c|c|}
\hline Side & Right & Left & Total \\
\hline No of patients & 9 & 11 & 20 \\
\hline Percentage & $45 \%$ & $55 \%$ & $100 \%$ \\
\hline
\end{tabular}

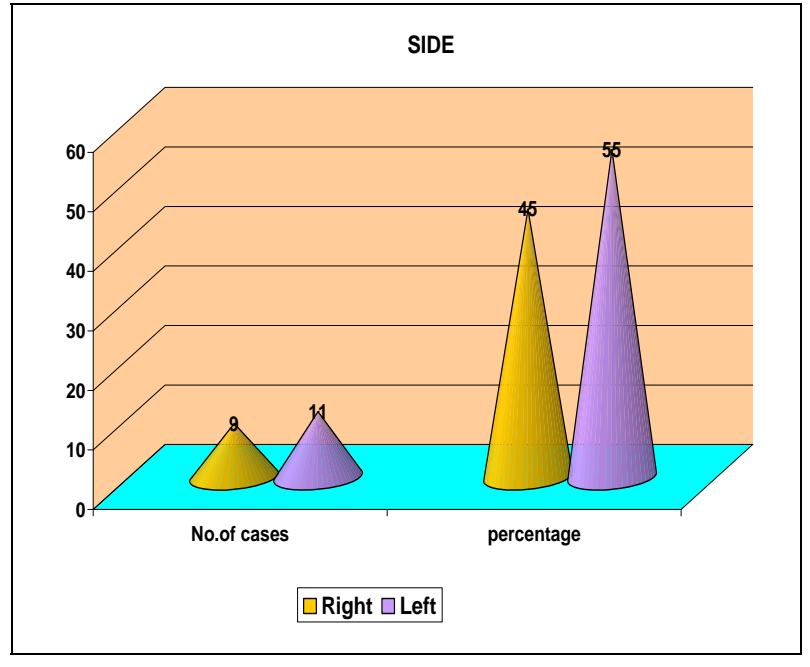

\section{Complications}

Among 20 patients three had following complications. One patient had superficial infection, which was controlled with oral antibiotics, second patient had deep infection with shoulder stiffness for which she underwent surgery i.e. implant removal done after third month of surgery and shoulder functions was improved. Third patient who was in on improper physiotherapy developed shoulder stiffness.

\begin{tabular}{|c|c|c|}
\hline Complication & No. of cases & Percentage \\
\hline Superficial wound infection & 1 & 5 \\
\hline $\begin{array}{c}\text { Deep wound infection with shoulder } \\
\text { stiffness }\end{array}$ & 1 & 5 \\
\hline Shoulder stiffness & 1 & 5 \\
\hline Without complications & 17 & 85 \\
\hline
\end{tabular}

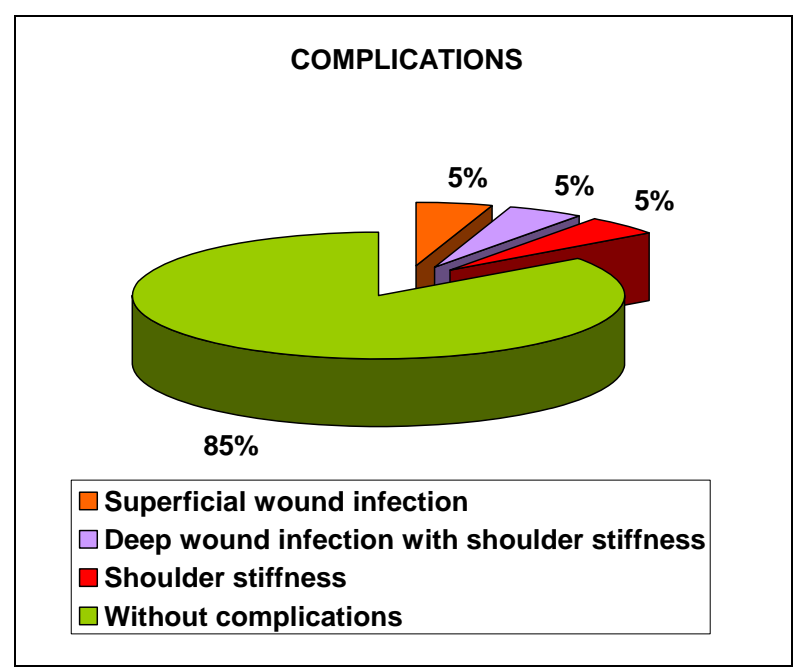

\section{Complications}

Superficial wound infection

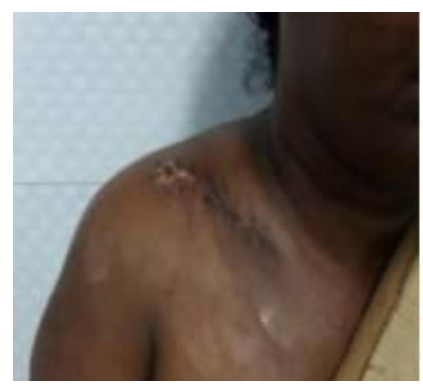

Shoulder stiffness

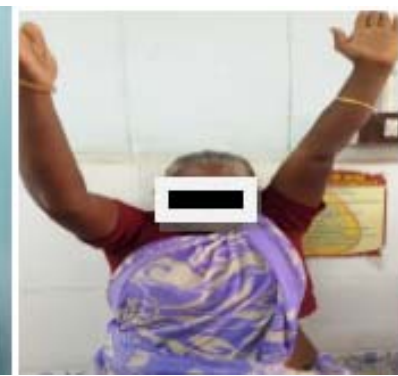

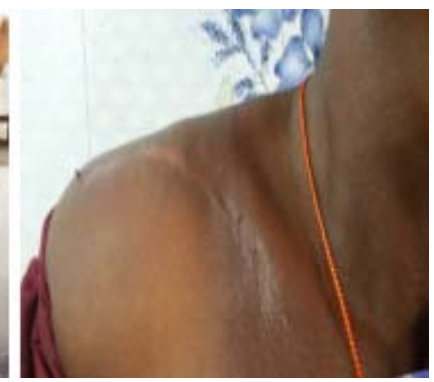




\section{University of California Los Angeles Shoulder Rating} Scale

Almost all 18 patients had a score above 27 with a good/excellent grade except for two patients. One patient had wound infection followed by shoulder stiffness and function improving after implant removal; and one patient was a 45 year old male who developed shoulder stiffness due to improper follow-up and physiotherapy.

\begin{tabular}{|c|c|c|}
\hline UCLA scale & No of patients & Percentage \\
\hline Good/excellent $(>27)$ & 18 & $90 \%$ \\
\hline Fair/poor $(<27)$ & 2 & $10 \%$ \\
\hline
\end{tabular}

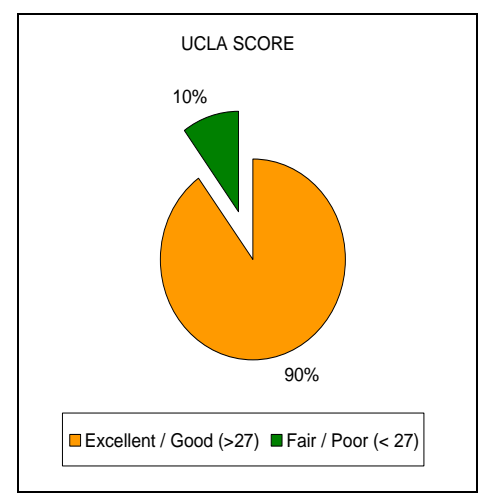

\section{Coraco clavicular distance}

Coracoclavicular distance was measured from superior surface of the coracoid to inferior surface of the clavicle. $\mathrm{P}$ value is 0.310 . No significant difference was found between Fracture side and normal side by coracoclavicular distance.

\begin{tabular}{|c|c|c|}
\hline & Fracture side & Normal side \\
\hline Mean & 0.861 & 0.827 \\
\hline SD & 0.107 & 0.102 \\
\hline p value & \multicolumn{2}{|c|}{0.310 Not significant } \\
\hline
\end{tabular}

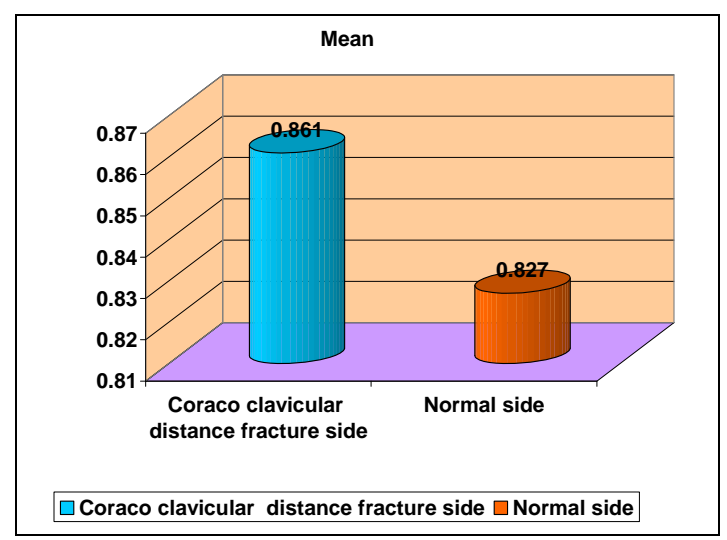

\section{Statistical Analysis}

The information collected regarding all the selected cases were recorded in a master chart. Data analysis was done with the help of computer by using SPSS software and Sigma Stat 3.5 version (2012). Using this software percentage, mean, standard deviation and ' $p$ ' value were calculated through One way ANOVA, and Chi square test and $\mathrm{P}$ value of $<0.05$ was taken as significant.

Time to bony union: In all patients union of bone was observed, and mean time required to bony union was 11.35 weeks (range from 9 to 13 weeks).

Patient Satisfaction: After the surgery, 18 patients were satisfied with their shoulder functions.

Range of Movements: Range of movements was well maintained in all patients except two patients.

\section{Case Illustrations \\ Case I}

\section{Radiological outcome}
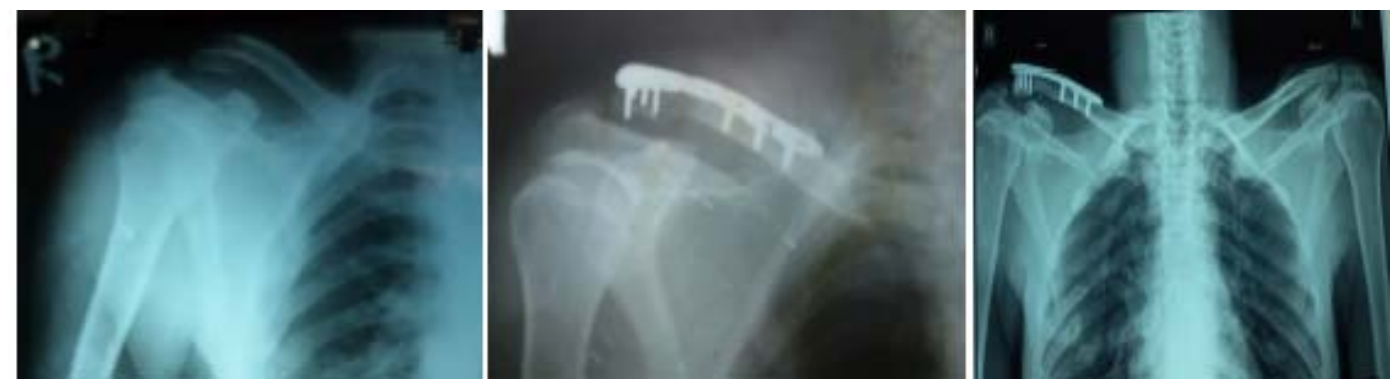

Clinical outcome

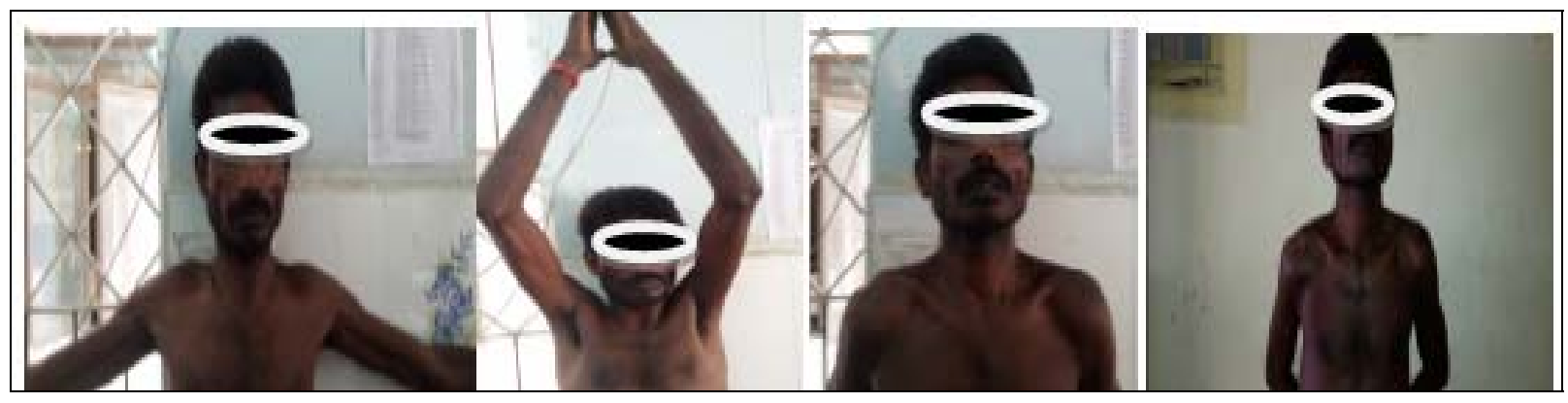


Case II

Radiological outcome

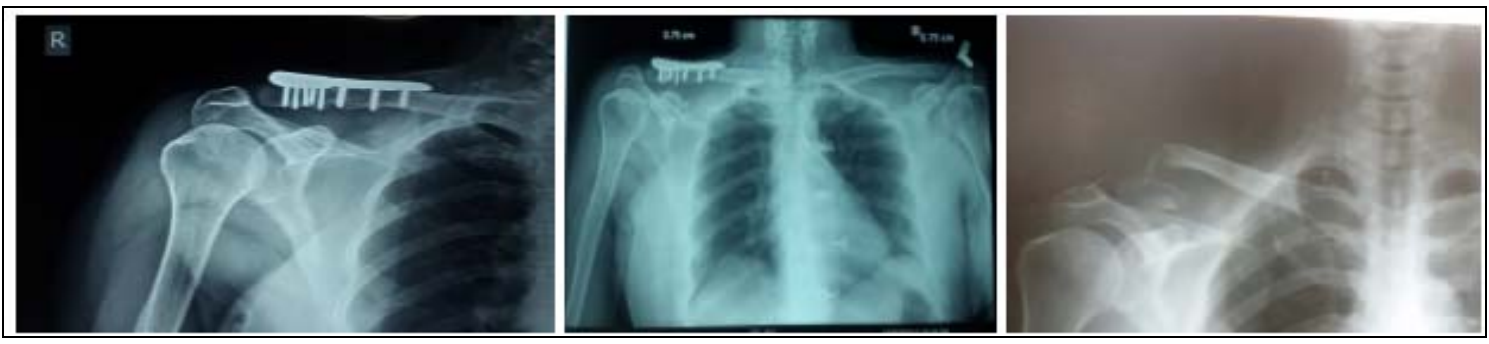

Clinical outcome

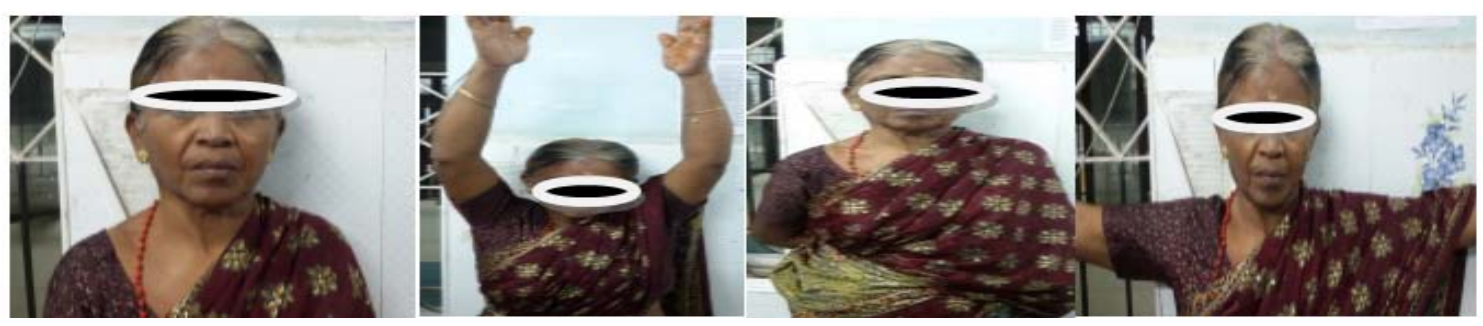

Case III

Radiological outcome

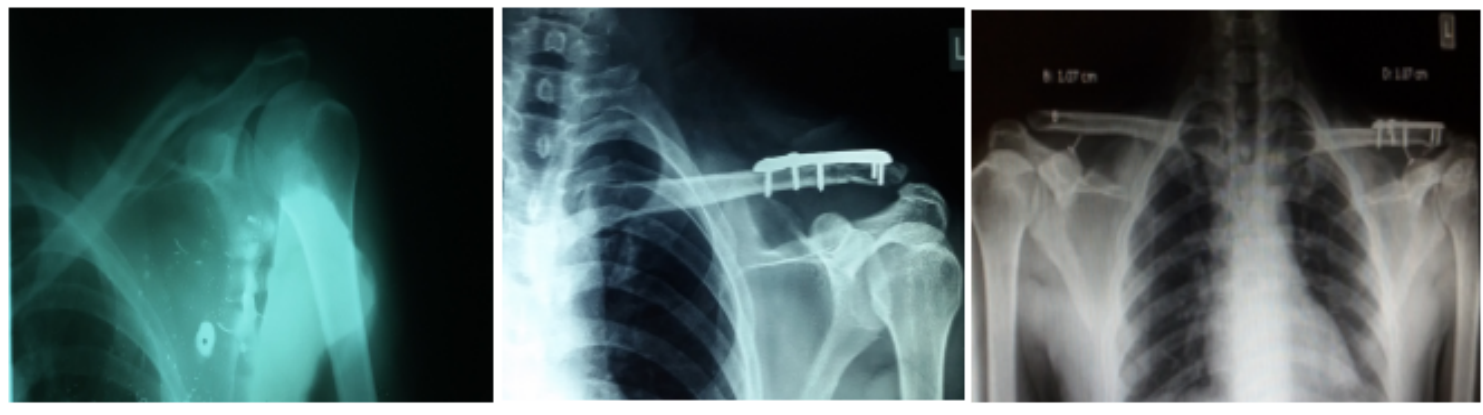

Clinical outcome

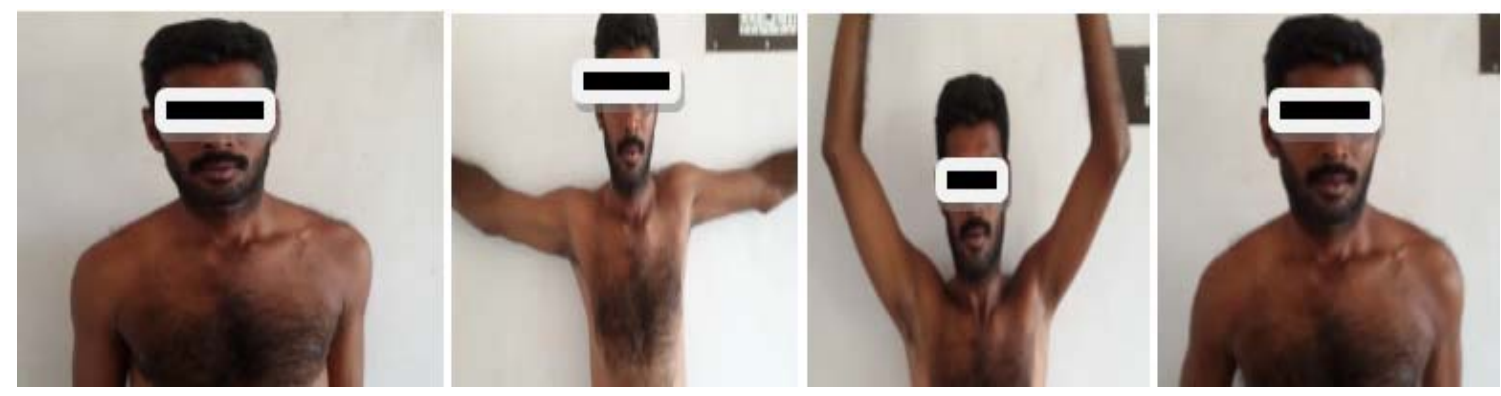

Case III

Radiological outcome
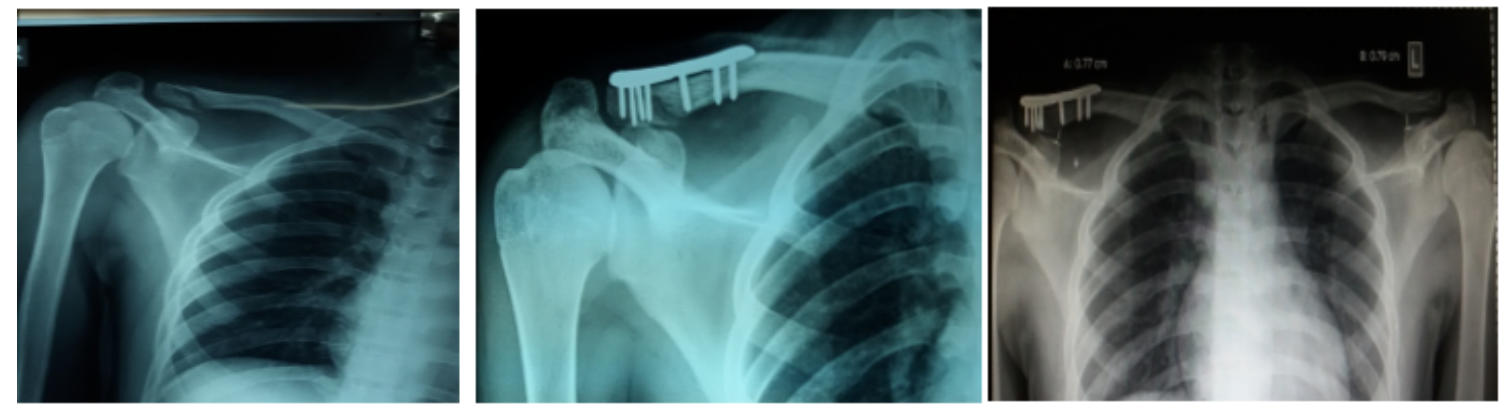

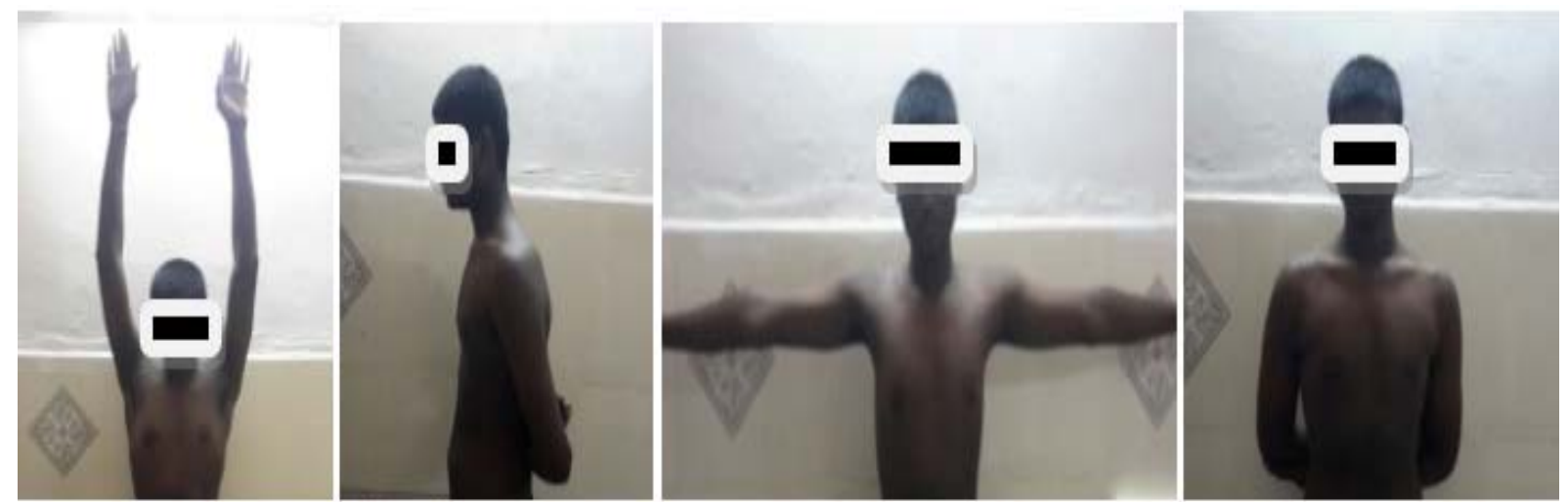

\section{Case V}

Radiological outcome
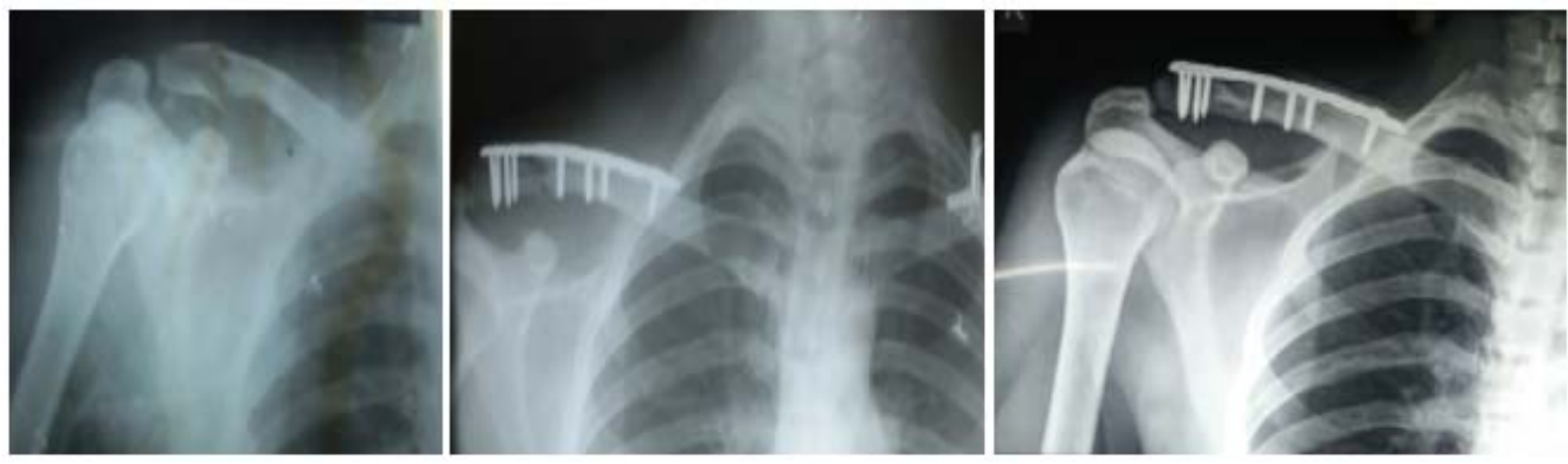

Clinical outcome
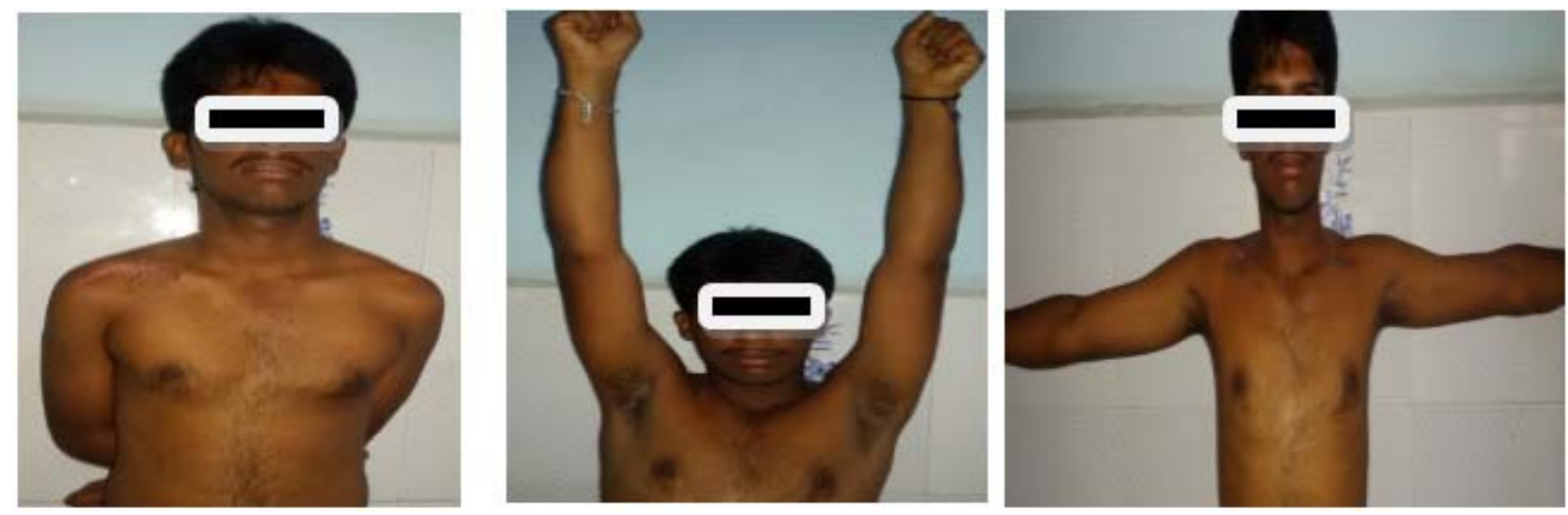

\section{Case VI}

\section{Radiological outcome}
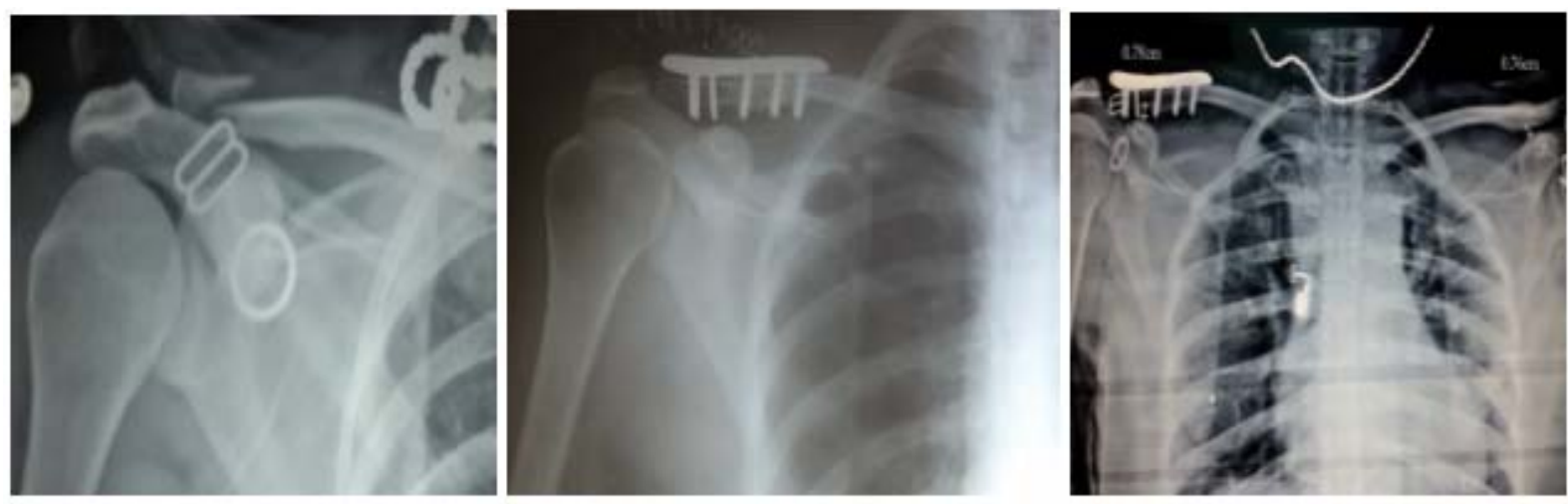


\section{Clinical outcome}
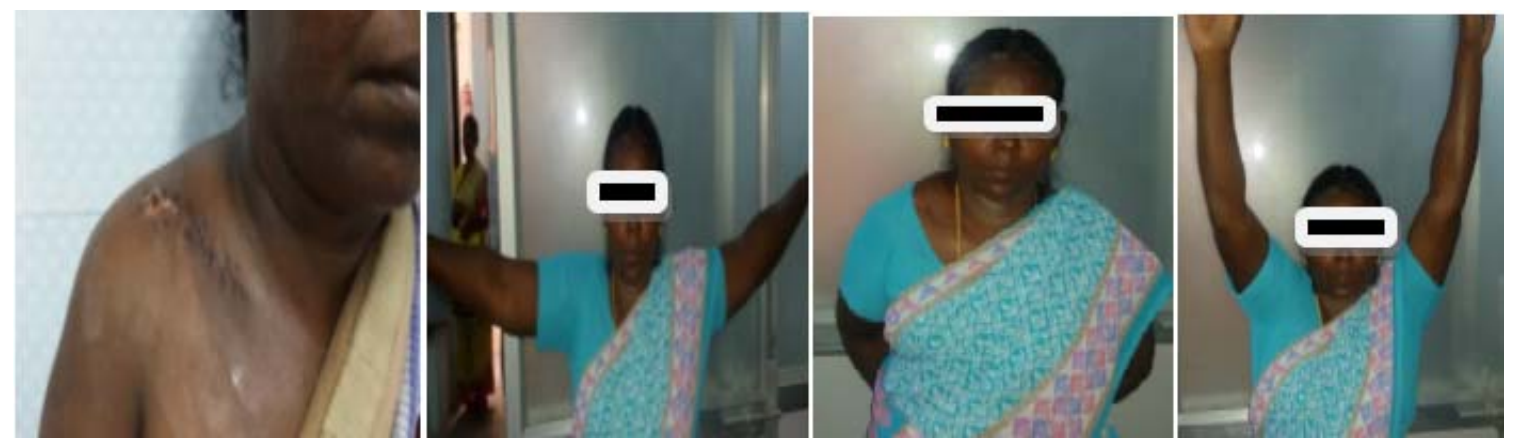

\section{Discussion}

Many different methods of fixations are available to treat the displaced lateral end of clavicle fractures and it produces satisfactory functional results. All these methods have their own advantages and disadvantages due to displaced nature of fractures of lateral end of clavicle. Neutralization of distracting forces at this site leads to union of fracture. The union of lateral end of clavicle fracture is a challenging one, because of communited, small, soft distal metaphyseal fragments and proximity to the acromioclavicular joint union of lateral end of clavicle fracture is a challenging one. So that various methods and techniques are described for achieving reduction and fixation.

\section{The following methods of fixation available}

After perfect reduction of the fracture ends, transacromial fixation with $\mathrm{K}$-wires with or without a wire cerclage.

Fixing the coracoid process to medial clavicle using a screw (Bosworth), nonresorbable slings, or ropes will reduce the fracture ends indirectly.

Clavicle hook plate - reduction achieved on the lateral end with a hook that is placed inferior to the acromion and by medially using plate and screw interface

T-shaped distal radius plates, clavicle plates with lateral extension- both ends are reduced and fixed with a plate and (locked) screws.

Specific advantages and complications for each method of fixation. There is high rate of infection and non-union in Kwires with cerclage method due to migration of the K-wires [26].

Extensive soft tissue dissection is required indirect reduction for the fracture with a screw, slings, or ropes to expose the fracture site and the coracoid process. Due to bore holes, complications like erosion and fractures can occur ${ }^{[47]}$. The time to full recovery is prolonged due to limited rotational movements of the clavicle because of coracoclavicular fixation ${ }^{[48]}$.

Good results are achieved by the use of clavicle hook plate in the last decade for lateral end of clavicle fracture and particularly it permit early mobilization in the postoperative period due to the rigid fixation. Short-term complicationssuch as subacromial osteolysis accompanied by pain and subacromial impingement in a small group of patients treated using this plate, thus requiring implant removal occurs, even though mid-term results of treatment of this plate indicated that there were no adverse effects on the acromioclavicular joint.

In these fractures a stable plate and screw fixation was achieved with locking plates, as described by Kalamaras, Daglar, and Herrma. They used plates that were not indicated for this fracture, although they are obtained satisfactory results with distal radius plates. In these study buttress effect of the articular surface provided by distal radius plates in a raft fashion placement of screws. In this study main complications are osteoporotic lateral fragment and screw pull-out from the plate because of too little grip in a small fragment.

Coracoclavicular fixation or Suture augmentation of the coracoclavicular ligaments in such cases are suggested by some authors ${ }^{[23,66]}$. Pull-out occurred in these cases because distal radius plate did not neutralize the downward forces acting on the lateral end of the clavicle fracture sufficiently. The precontoured locking clavicle plates have special design for good stability for lateral fragment: they have diverging screw angles in three rows with double screws, which give much more pull-out strength and resist shear forces that act on the short and soft metaphyseal fragment. We did not meet pull-out of plate in all our patients, even when there is horizontal split of the lateral $1 / 3^{\text {rd }}$ of clavicle in the 11 months mean follow-up.

Another complication we encountered with this implant in our study was deep infection followed by shoulder stiffness required implant removal to relieve symptoms.

Very short period after surgery 18 out of 20 patients attained prior to injury levels of activity. Fracture was immobilized adequately \& early pain-free post-op mobilization was possible because of the stable fixation. High UCLA shoulder rating scale it's an indirect evidence of the normal shoulder function with little or no sign of any negative influence on day to day activities.

Precontoured locking compression plate is better than the conventional clavicle plate, as an ideal implant for displaced lateral $1 / 3^{\text {rd }}$ fractures of clavicle. The profound knowledge of lateral end clavicle anatomy and close relation to acromioclavicular joint also requires. This procedure requires sufficient surgical exposure, perfect anatomical reduction with this specific pre-contoured plate.

Only a few number of patients were included in our study which is the main limitation. Several biases occur in this study. So any conclusions drawn should be carefully analysed because of small number of patients undergoing this study. However, the incidence of the lateral $1 / 3^{\text {rd }}$ clavicle fracture is uncommon it makes difficulties to recruit many patients.

We achieved good initial results with the precontoured locking plate in all patients in this prospective study, even though small numbers of patients were included in our study. In our opinion, pre-contoured locking plate is one among the most technically demanding methods in treating lateral end of clavicle fractures. When it was used correctly it does not damage surrounding soft tissue and provides a stable and rigid fixation. Hence it will help in the postoperative period for early mobilization and union of fractures in short time. 
All patients with distal $1 / 3^{\text {rd }}$ clavicle fracture Neer type II in our study were treated with primary precontoured locking plate fixation. 18 patients had good bone union with return of full range of shoulder movements. There was good patient satisfaction except two patients. One patient had deep wound infection followed by shoulder stiffness and other patient who was not on improper physiotherapy. Implant was removed in the case with deep wound infection. Refracture was not seen in the mean 11 months follow-up.

\section{Conclusion}

This study shows that early primary fixation of distal third fractures of clavicle with precontoured locking plates result in earlier return to function.

1. Results with using this plate are encouraging because this method has the advantage of achieving a stable fracture fixation using multidirectional locking screws in a small, soft distal clavicular fragment, which helps in early mobilization of shoulder joint

2. There were no major complications such as subacromial impingement or rotator cuff injury and thus, don't require implant removal.

3. Radiologically coracoclavicular distance was not significantly different between the injured and normal shoulders at the final follow-up.

To conclude, precontoured locking plate provides an acceptable alternative method for the internal fixation for displaced distal clavicular fractures (Neer type II) and delivers good results.

\section{Reference}

1. Rokito AS, Zuckerman JD, Shaari JM, Eisenberg DP, Cuomo F, Gallagher MA. A comparison of nonoperative and operative treatment of type II distal clavicle fractures. Bull Hosp Jt Dis. 2002; 61:32-39.

2. Robinson CM, Cairns DA. Primary nonoperative treatment of displaced lateral fractures of the clavicle. J Bone Joint Surg Am. 2004; 86-a:778-782.

3. Neer CS. Non-union of the clavicle. JAMA 1960; 172:1006-11

4. Neer CS II. Fractures of the distal third of the clavicle. Clin Orthop. 1968; 58:43-50.

5. Neer CS II. Fracture of the distal clavicle with detachment of the coraco-clavicular ligaments in adults. J Trauma. 1963; 3:99-110.

6. Edwards DJ, Kavanagh TG, Flannery MC. Fractures of the distal clavicle: a case for fixation. Injury. 1992; 23:44-6. 25. Craig EV. Fractures of the clavicle. In: Rockwood CA Jr, Green DP, Bucholz RW, eds. Fractures in adults. Third ed. Philadelphia, etc: JB Lippincott Company, 1991:928-90.

7. Nordqvist A, Peterson C, Redlund-Johnell I. The natural course of lateral clavicle fracture: 15 (11-21) year followup of 110 cases. Acta Orthop Scand. 1993; 64:87-91.

8. Kabak S, Halici M, Tuncel M, Avsarogullari L, Karaoglu $\mathrm{S}$. Treatment of midclavicular non-union: comparison of dynamic compression plating and low-contact dynamic compression plating techniques. J Shoulder Elbow Surg. 2004; 13:396-403, 13396.

9. Golish SR, Oliviero JA, Francke EI, Miller MD. A biomechanical study of plate versus intramedullary devices for midshaft clavicle fixation. J Orthop Surg. 2008; $3: 28.328$.

10. Neer CS. 2nd Fractures of the distal third of the clavicle. Clin Orthop Relat Res. 1968; 58:43-50.

11. Nordqvist A, Peterson C, Redlund-Johnell I. The natural course of lateral clavicle fracture. 15 (11-21) year followup of 110 cases. Acta Orthop Scand. 1993; 64(1):87-91.

12. Robinson CM. Fractures of the clavicle in the adult. Epidemiology and classification. J Bone Joint Surg Br. 1998; 80(3):476-84.

13. Allman FL. Jr Fractures and ligamentous injuries of the clavicle and its articulation. J Bone Joint Surg Am. 1967; 49(4):774-84.

14. Oh JH, Kim SH, Lee JH, Shin SH, Gong HS. Treatment of distal clavicle fracture: a systematic review of treatment modalities in 425 fractures. Arch Orthop Trauma Surg. 2011; 131(4):525-33.

15. Bisbinas I, Mikalef P, Gigis I, Beslikas T, Panou N, Christoforidis I. Management of distal clavicle fractures. Acta Orthop Belg. 2010; 76(2):145-9.

16. Robinson CM, Cairns DA. Primary nonoperative treatment of displaced lateral fractures of the clavicle. $\mathrm{J}$ Bone Joint Surg Am. 2004; 86-A(4):778-82.

17. Martetschlager F, Kraus TM, Schiele CS. Treatment for unstable distal clavicle fractures (Neer 2) with locking Tplate and additional PDS cerclage. Knee Surg Sports Traumatol Arthrosc. 2013; 21(5):1189-94.

18. Good DW, Lui DF, Leonard M, Morris S, McElwain JP. Clavicle hook plate fixation for displaced lateral-third clavicle fractures (Neer type II): a functional outcome study. J Shoulder Elbow Surg. 2012; 21(8):1045-8.

19. Esenyel CZ, Ceylan HH, Ayanoğlu S, Kebudi A, Adanir O, Bülbül M. Treatment of Neer Type 2 fractures of the distal clavicle with coracoclavicular screw. Acta Orthop Traumatol Turc. 2011; 45(5):291-6.

20. Wu K, Chang $\mathrm{CH}$, Yang RS. Comparing hook plates and Kirschner tension band wiring for unstable lateral clavicle fractures. Orthopedics. 2011; 34(11):e718-23.

21. Jou IM, Chiang EP, Lin CJ, Lin CL, Wang PH, Su WR. Treatment of unstable distal clavicle fractures with Knowles pin. J Shoulder Elbow Surg. 2011; 20(3):414-9.

22. Hessmann M, Kirchner R, Baumgaertel F, Gehling H, Gotzen L. Treatment of unstable distal clavicular fractures with and without lesions of the acromioclavicular joint. Injury. 1996; 27(1):47-52.

23. Kalamaras M, Cutbush K, Robinson M. A method for internal fixation of unstable distal clavicle fractures: early observations using a new technique. J Shoulder Elbow Surg. 2008; 17(1):60-2.

24. Kang HJ, Kim HS, Kim SJ, Yoo JH. Osteosynthesis of symptomatic no unions of type II fractures of the distal clavicle using modified locking T-plate and bone grafting. J Trauma Acute Care Surg. 2012; 72(2):E14-9.

25. Hohmann E, Hansen T, Tetsworth K. Treatment of Neer type II fractures of the lateral clavicle using distal radius locking plates combined with Tightrope augmentation of the coraco-clavicular ligaments. Arch Orthop Trauma Surg. 2012; 132(10):1415-21.

26. Kona J, Bosse MJ, Staeheli JW, Rosseau RL. Type II distal clavicle fractures: a retrospective review of surgical treatment. J Orthop Trauma. 1990; 4:115-120.

27. Eberle C, Fodor P, Metzger U. Hook plate (so-called Balser plate) or tension banding with the Bosworth screw in complete acromioclavicular dislocation and clavicular fracture. Z Unfallchir Versicherungsmed. 1992; 85:134139.

28. Hill JM, McGuire MH, Crosby LA. Closed treatment of displaced middle-third fractures of the clavicle gives poor 
results. J Bone Joint Surg Br. 1997; 79B:537-539.

29. Perren S, Claes L. Biology and biomechanics in fracture management. In: Ruedi T, Murphy W, eds. AO Principles of Fracture7Management. New York: Theime; 2000, 731 .

30. Renfree T, Conrad B, Wright T. Biomechanical comparison of Contemporary clavicle fixation devices. J Hand Surg Am. 2010; 35:639-644.

31. Huang JI, Too good P, Chen MR. Clavicular anatomy and the applicability of precontoured plates. J Bone Joint Surg Am. 2007; 89A:2260-2265.

32. Cave AJ. The nature and morphology of the costoclavicular ligament. J Anat 1961; 95:170-179.

33. Chen $\mathrm{CH}, \mathrm{Ch} \mathrm{WJ}$, Shih $\mathrm{CH}$. Surgical treatment for distal clavicle fractures with coracoclavicular ligament disruption. J Trauma. 2002; 52:7-8.

34. Edwards DJ, Kavanagh TG, Flannery MC. Fractures of the distal clavicle: a case for fixation. Injury. 1992; 23:44-46

35. Kona J, Bosse JM, Staeheli JW. Type II distal clavicle fractures: a retrospective review of surgical treatment. J Orthop Trauma. 1990; 4:115-120.

36. Moseley HF. The clavicle: its anatomy and function. Clin Orthop. 1968; 58:17-27.

37. Webber MC, Haines JF. The treatment of lateral clavicle fractures. Injury. 2000; 31:175-179.

38. Zdero R, Yoo D, MacConnell A. A biomechanical study of acromioclavicular joint fixation. J Orthop Trauma. 2007; 21:248-253.

39. Canadian Orthopaedic Trauma Society (MD McKee, principal investigator). Plate fixation versus nonoperative care for acute, displaced midshaft fractures of the clavicle. J Bone Joint Surg. 2007; 89A:1-11.

40. Crenshaw AH. Fractures of the shoulder girdle arm and forearm. In Willis CC, ed. Campbell's Operative orthopaedics, 8th ed. St. Louis: Mosby-Year Book. 1992, 989-995.

41. Robinson CM. Fractures of the clavicle in the adult. $\mathrm{J}$ Bone Joint Surg Br. 1998; 80B:476-484.

42. Spar I. Total claviculectomy for pathological fractures. Clin Orthop. 1977; 129:236-237.

43. Stanley D, Trowbridge EA, Norris SH. The mechanism of clavicular fracture. A clinical and biochemical analysis. J Bone Joint Surg Br. 1988; 70B:461-464.

44. Robinson CM, Cairns DA. Primary nonoperative treatment of displaced lateral fractures of the clavicle. J Bone Joint Surge Am. 2004; 86A:778-782.

45. Nowak J, Holgersson M, Larsson S. Can we predict longterm sequelae after fractures of the clavicle based on initial findings? A prospective study with 9 to 10 years follow-up. J Shoulder Elbow Surg. 2004; 13:479-486.

46. Beaton DE, Wright JG, Katz JN. Development of the Quick DASH: comparison of three item-reduction approaches. J Bone Joint Surg Am. 2005; 87:1038-1046.

47. Moneim MS, Balduini FC. Coracoid fracture as a complication of surgical treatment by coracoclavicular tape fixation. A case report. Clin Orthop Relat Res. 1982; 168:133-135

48. Flinkkila T, Ristiniemi J, Hyvonen P, Hamalainen M. Surgical treatment of unstable fractures of the distal clavicle: a comparative study of Kirschner wire and clavicular hook plate fixation. Acta Orthop Scand. 2002; 73:50-53.

49. Tiren D, Van Bemmel AJ, Swank DJ, Van der Linden FM. Hook plate fixation of acute displaced lateral clavicle fractures: mid-term results and a brief literature overview. J Orthop Surg Res. 2012; 7:2.

50. Robinson CM, Court-Brown CM, McQueen MM, Wakefield AE. Estimating the risk of non-union following nonoperative treatment of a clavicular fracture. J Bone Joint Surg Am. 2004; 86:1359-65.

51. Edelson JG. The bony anatomy of clavicular malunions. J Shoulder Elbow Surg. 2003; 12:173-8.

52. McKee MD, Wild LM, Schemitsch EH. Midshaft malunions of the clavicle. Surgical technique. J Bone Joint Surg Am.2004; 86(1):37-43.

53. Barbier O, Malghem J, Delaere O, Vande Berg B, Rombouts JJ. Injury to the brachial plexus by a fragment of bone after fracture of the clavicle. J Bone Joint Surg Br. 1997; 79:534-6.79534 1997

54. Chen CE, Liu HC. Delayed brachial plexus neuropraxia complicating malunion of the clavicle. Am J Orthop. 2000; 29:321-2.29321

55. Ring D, Holovacs T. Brachial plexus palsy after intramedullary fixation of a clavicular fracture. A report of three cases. J Bone Joint Surg Am. 2005; 87:18347.871834 .

56. Coupe BD, Wimhurst JA, Indar R, Calder DA, Patel AD. A new approach for plate fixation of midshaft clavicular fractures. Injury. 2005;36:1166-71.361166 2005

57. Flinkkilä T, Ristiniemi J, Lakovaara M, Hyvönen P, Leppilahti J. Hook-plate fixation of unstable lateral clavicle fractures: a report on 63 patients. Acta Orthop. 2006; 77:644-9.77644

58. Jinkins WJ Jr. Congenital pseudarthrosis of the clavicle. Clin Orthop Relat Res. 1969; 62:183-6.

59. Saint-Pierre L. Pseudarthrose congénitale de la clavicule droite. Ann d'Anatom Patholol d'Anatom Normal MedChir. 1930; 7:625.

60. Manashil G, Laufer S. Congenital pseudarthrosis of the clavicle: report of three cases. AJR Am J Roentgenol. 1979; 132(4):678-9.

61. Gibson DA, Carroll N. Congenital pseudarthrosis of the clavicle. J Bone Joint Surg Br. 1970; 52(4):629-43.

62. Beslikas TA, Dadoukis DJ, Gigis IP, Nenopoulos SP, Christoforides JE. Congenital pseudarthrosis of the clavicle: a case report. J Orthop Surg (Hong Kong). 2007; 15(1):87-90.

63. The Development and Ossification of the Human Clavicle. J Anat Physiol. 1913; 47(Pt 2):225-34.

64. Daglar B, Delialioglu OM, Minareci E, Tasbas BA, Bayrakci K, Gunel U. An alternative fixation method for the treatment of unstable distal clavicle fractures: locked distal radius plate. Acta Orthop Traumatol Turc. 2009; 43:324-330.

65. Herrmann S, Schmidmaier G, Greiner S. Stabilisation of vertical unstable distal clavicular fractures (Neer 2b) using locking T-plates and suture anchors. Injury. 2009; 40:236-239.

66. L'Insalata JC, Warren RF, Cohen SB, Altchek DW, Peterson MG. A self-administered questionnaire for assessment of symptoms and function of the shoulder. J Bone Joint Surg Am. 1997; 79:738-748.

67. Ballmer FT, Gerber C. Coracoclavicular screw fixation for unstable fractures of the distal clavicle. A report of five cases. J Bone Joint Surg. 1991; 73-B:291-294.

68. Fann CY, Chiu FY, Chuang TY, Chen CM, Chen TH. Transacromial Knowles pin in the treatment of Neer type 2 distal clavicle fractures. A prospective evaluation of 32 cases. J Trauma. 2004; 56:1102-1105. 
69. Fazal MA, Saksena J, Haddad FS. Temporary coracoclavicular screw fixation for displaced distal clavicle fractures. J Orthop Surg (Hong Kong). 2007; 15:9-11.

70. Flinkkilä T, Ristiniemi J, Hyvönen $P$, Hämäläinen $M$. Surgical treatment of unstable fractures of the distal clavicle: a comparative study of Kirschner wire and clavicular hook plate fixation. Acta Orthop Scand. 2002; 73:50-53.

71. Haidar SG, Krishnan KM, Deshmukh SC. Hook plate fixation for type II fractures of the lateral end of the clavicle. J Shoulder Elbow Surg. 2006; 15:419-423.

72. Lyons FA, Rockwood CA Jr. Migration of pins used in operations on the shoulder. J Bone Joint Surg. 1990; 72A:1262-1267.

73. Ebraheim NA, Mekhail AO, Darwich M. Open reduction and internal fixation with bone grafting of clavicular nonunion. J Trauma. 1997; 42:701-4.42701 1997

74. Jupiter JB, Leffert RD. Non-union of the clavicle. Associated complications and surgical management. J Bone Joint Surg Am. 1987; 69:753-60.69753 1987

75. Eskola A, Vainionpää S, Myllynen $P$, Pätiälä $H$, Rokkanen P. Surgery for ununited clavicular fracture. Acta Orthop Scand. 1986; 57:366-7.57366

76. Marti RK, Nolte PA, Kerkhoffs GM, Besselaar PP, Schaap GR. Operative treatment of mid-shaft clavicular non-union. Int Orthop. 2003; 27:131-5.27131

77. Klein SM, Badman BL, Keating CJ, Devinney DS, Frankle MA, Mighell MA. Results of surgical treatment for unstable distal clavicular fractures. J shoulder elbow surg. 2010; 19:1049-1055. 